\title{
Antibiotic resistance in Canada at the dawn of the new millennium - A model for the developed world?
}

\author{
John M Conly MD FRCPC 1 , B Lynn Johnston MD FRCPC ${ }^{2}$
}

A ntibiotic resistance has increased dramatically and rapidly during the 1990s, and it is widely acknowledged to be a serious threat to the treatment of infectious diseases on a global basis (1-6). The morbidity, mortality and economic burden of infections with multiply drug resistant organisms, for which there are no effective therapies, pose an increasing burden for health care systems worldwide; Canada is no exception (7). Without effective public health strategies, grim warnings of a postantibiotic era may become a reality. In addition to significant increases in costs and greater toxicity of newer drugs, antibiotic-resistant organisms are continuously eroding the therapeutic armamentarium, leaving fewer or no alternative agents available. Although much has been written about antibiotic resistance during the past few years, it is noteworthy and relevant that both the World Health Organization (WHO) (8) and the Centers for Disease Control and Prevention (CDC) (9), have released reports on this topic this past June.

The WHO report, entitled Overcoming Antimicrobial Resistance (8), gives a stark warning that, at the dawn of a new millennium, humanity is faced with a crisis, where rising rates of drug resistance in many microorganisms could rob the world of its opportunity to cure many common infectious diseases. The report (8) describes multidrug-resistant (two or more firstline drugs) Mycobacterium tuberculosis rates of over $10 \%$ in Estonia, Latvia, and in parts of Russia and China; complete loss of the three most commonly used antimalarial drugs in Thailand due to resistance; lamivudine resistance rates of $30 \%$ to hepatitis B virus; cotrimoxazole-resistant Shigella dysenteriae rates of nearly $100 \%$ in certain parts of India; and rates of hospital-acquired, methicillin-resistant Staphylococcus aureus (MRSA) of 60\% in several industrialized nations. Although the report acknowledges that antibiotic resistance is a natural biological phenomenon, it suggests that it becomes a significant public health burden when it is amplified by human misuse and neglect. Overuse of antibiotics in developed nations and, paradoxically, both misuse and underuse in developing nations have contributed to the burden. Due to fears of resistance, many health care providers are avoiding narrow spectrum drugs in favour of broader spectrum antibiotics that have wider applications and greater impact on the natural flora. The report also indicated that unethical pharmaceutical companies sometimes pay a commission for recommending more expensive broader spectrum medications when cheaper narrow spectrum alternatives would suffice, resulting in a smaller, highly priced pool of antibiotics for a larger spectrum of infectious diseases (8). The WHO report suggests developing a global strategy to contain resistance and to build alliances involving all healthcare providers - countries, governments, international organizations, nongovernmental organizations and both the private and public health care sectors - in an effort to quell the rising tide of resistance. The WHO's Global Strategy for the Containment of Antimicrobial Resistance offers a series of recommendations aimed at enabling countries to define and implement national policies designed to maintain antimicrobial efficacy.

In the United States, a draft version of the document entitled Public Health Action Plan to Combat Antimicrobial Resistance (9) was also made available in June of this year. The Action Plan, which was developed by an interagency task

\footnotetext{
${ }^{1}$ University Health Network, University of Toronto, Toronto, Ontario; ${ }^{2}$ Queen Elizabeth II Health Sciences Centre and Dalhousie University, Halifax, Nova Scotia

Correspondence: Dr John Conly, Department of Medicine, Division of Infectious Diseases, Suite 13-118 Norman Urquhart Wing, Toronto General Hospital, University Health Network, 200 Elizabeth Street, Toronto, Ontario M5G 2C4. Telephone 416-340-4858, fax 416-340-5047, email john.conly@uhn.on.ca and Dr Lynn Johnston, Room 5014 ACC, Queen Elizabeth II Health Sciences Centre, 1278 Tower Road, Halifax, Nova Scotia B3H 2Y9. Telephone 902-473-8477, fax 902-473-7394, e-mail ljohnsto@is.dal.ca and
} 
force, including the CDC, the Food and Drug Administration, and the National Institutes of Health, provides a blueprint for specific, coordinated actions to address the emerging threat of antimicrobial resistance. Similar to the WHO report, the document emphasizes that drug-resistant pathogens are a growing menace to all people regardless of age, sex or background. The Action Plan outlines 11 priority items relating to surveillance, prevention and control, research, and new product development. The prevention and control section focuses not only on the human but also on agricultural issues, and the commonalties between the two are being increasingly recognized.

In Canada, systematic efforts for controlling antibiotic resistance began in 1997 following a landmark consensus conference entitled Controlling Antimicrobial Resistance: An Integrated Action Plan for Canada (10). The conference, cosponsored by Health Canada and the Canadian Infectious Disease Society, developed an action plan that emphasized three components - antimicrobial stewardship, infection prevention and control, and surveillance - to monitor resistance trends. The Canadian Committee on Antibiotic Resistance was formed following the national consensus conference; it is a multidisciplinary group performing a collating and coordinating role for stakeholder groups across Canada. With initial funding from Health Canada allowing the recruitment of an executive director, it has taken an active, multifaceted advocacy and promotion role, which includes distributing antibiotic resistance tool kits to all Canadian physicians and veterinarians, hosting a web site (11) to provide an overview of Canadian antibiotic resistance activities, working with the agrifood industry and attempting to establish a national surveillance system. Through an agreement with Intercontinental Medical Statistics (IMS) HEALTH Canada and its Compuscript database, complete antimicrobial consumption data on all classes of oral antimicrobials in Canada are provided to the website. Together with current trending reports of antimicrobial resistance patterns in Canada from various national and regional surveillance systems, either linked or posted on the site, a composite portrait of the Canadian efforts against antibiotic resistance is provided.

Many microorganisms have exhibited increasing rates of resistance to commonly used antimicrobials, including MRSA, vancomycin-resistant enterococci (VRE), multiply antibioticresistant Shigella species, extended spectrum beta-lactam (ESBL)-resistant enteric Gram-negative bacilli (Klebsiella and Enterobacter species) and penicillin-resistant Streptococcus pneumoniae (PRSP). Some of these organisms such as MRSA, VRE and ESBL are most often associated with patients in health care facilities, whereas PRSP and multiply resistant Shigella species are more common in the community. The epidemiology of resistance in the most commonly encountered antibiotic-resistant organisms in Canada and an update of trends in antimicrobial prescribing are described in the ensuing paragraphs.

The prevalence of MRSA was less than $5 \%$ in the late 1960 s and 1970 s in most hospital settings worldwide, but in the 1980s it had increased to as high as $40 \%$ in many hospitals in the United States and Europe $(12,13)$. The first MRSA isolate was reported in Canada in 1981 (14), and since then MRSA has been reported in both acute care and long term care facilities $(15,16)$. Recent data from the Canadian Nosocomial Infection Surveillance Program (CNISP), a collaborative effort between the Population and Public Health Branch (formerly the Laboratory Centre for Disease Control), Health Canada and the Canadian Hospital Epidemiology Committee, a subcommittee of the Canadian Infectious Disease Society has revealed that the proportion of $S$ aureus isolates that are reported as MRSA in their respective microbiology laboratories has increased from $0.5 \%$ in 1995 to $3.8 \%$ in 1997 (17). There was a further increase to $6.1 \%$ in $1999(0.3 / 1000$ admissions in 1995 to $4.3 / 1,000$ admissions in 1999) (18). The rates of MRSA vary markedly across the country, with central Canada (Ontario and Quebec) experiencing the bulk of MRSA, and the eastern and prairie regions experiencing much less. Most of the increase in MRSA has occurred in Ontario and British Columbia. Some of the increase has been attributed to a specific strain described initially in Ontario, which has several features that may ease its spread throughout health care facilities (19).

In recent years, the prevalence of VRE as a percentage of all nosocomial enterococcal infections in the United States has increased from $0.3 \%$ in 1989 to $23 \%$ in $1999(20,21)$. The overall percentage of nosocomial VRE isolates reported to the National Nosocomial Infection Surveillance System of the CDC in intensive increase care units reveals a similar increase, from $0.4 \%$ to $23 \%$ between 1989 and 1999. The first isolate of VRE in Canada was reported in 1993 (22), and the first outbreak, reported in 1995, involved 38 patients (23), of whom all but one was colonized. The first prevalence survey for VRE in Canada, conducted over a four-week period between January and March 1996, found a rate of $0.1 \%$ among high risk patients in a hospital with no outbreak and $3.7 \%$ among high risk patients in an endemic hospital (24). The second prevalence survey, performed in September 1997, found a rate of only $0.2 \%$ (personal communication, M Ofner-Agostini). A VRE Passive Reporting Network established within CNISP identified 1315 cases of VRE throughout Canada between 1994 and the end of 1998 , with less than $5 \%$ of cases identified as representing infection (25). In the first year of data collection for the VRE Incidence Surveillance Program, 95 cases of VRE were reported, a rate of $0.19 / 1000$ patient admissions and representing $0.55 \%$ of enterococcal isolates from the participating facilities (26). Despite the close physical proximity of Canada to the United States, VRE has not attained the same colonization rate in Canada and is very rarely encountered as a cause of infection.

An increasing prevalence of PRSP in Europe, South Africa and the United States was noted between 1974 and 1984, followed by the emergence of strains with resistance to multiple antibiotics. The prevalence of $S$ pneumoniae with reduced susceptibility to penicillin varies markedly around the world, with rates of up to $40 \%$ in several areas of the United States and to $70 \%$ in Korea. Several Canadian studies $(10,27,28)$ reveal that $S$ pneumoniae strains with reduced susceptibility to penicillin (both intermediate and high level resistance) have increased significantly, from less than $2 \%$ in the late 1980 s to $16 \%$ in 1998 according to one surveillance system in Canada. Recent 
data suggest that up to $5 \%$ of isolates have high levels of penicillin resistance. However, in one surveillance system, there has been a decrease in PRSP to 12\% during 1999 (28). In addition another Canadian surveillance system has described a decline in PRSP in the past two years (29). It is not known if this is related to changes in beta-lactam prescribing patterns in Canada, which have been declining, or whether it is a spurious decline.

The growth in antibiotic use, and particularly inappropriate use, is a global phenomenon and Canada is no exception. Among industrialized nations, France, Australia, the United States, Canada, Italy and the United Kingdom have the highest rates of oral antimicrobial prescriptions, ranging from 33 to 16 defined daily doses/1000 population/day (30). The Compuscript database of IMS HEALTH Canada reveals that approximately 25 million prescriptions for oral antibiotics were dispensed in 1999, making them the third most commonly prescribed class of agents, after cardiovascular and psychotherapeutic drugs (31). Based on recent Canadian data, 51\% of antibiotics are being prescribed for patients with upper respiratory tract infections, the common cold and other viral infections for which antibiotics are ineffective (32). These data are consistent with estimates by the CDC suggesting that as many as half of all antibiotic prescriptions are unnecessary. In addition, it is thought that significant costs are being incurred through the excessive use of expensive broad spectrum agents. In Canada, annual expenditures for antibiotics exceed $\$ 485$ million (33).

The data for oral antibiotic prescriptions in Canada from 1995 to March 2000 show that there has been a substantial decrease in the number of prescriptions $(11,34)$. By total prescriptions dispensed annually per 1000 population and adjusting for differences in population between 1995 and 2000 (35), oral, solid and liquid antimicrobial consumption in Canada decreased by $11 \%$ between 1995 and 2000, with total beta-lactam consumption declining by $16.2 \%$ during this same period. Using the number of prescriptions dispensed based on a 12-month moving annual total, the overall decrease between 1995 and 2000 is 29.8\% and between 1997 and March 2000 is $24 \%$. Although some efforts to promote judicious prescribing began in the mid-1990s, systematic efforts began in 1997, following the consensus conference (10) where national goals were set to reduce the number of antimicrobial prescriptions for respiratory infections by $25 \%$. Many regions and provinces in Canada have initiated programs to promote judicious antimicrobial prescribing (36-38), and the programs have had significant impact within their respective regions.

With the adoption of the Canadian consensus plan by jurisdictions and regions across Canada, it is hoped that the favourable trends will continue. The WHO, in its report on the growing threat of antimicrobial resistance, cited the recent decreases in antimicrobial prescribing in Canada and suggested that the work done in Canada could be a model for the developed world $(8,39)$.

\section{REFERENCES}

1. Report of the ASM Task Force on Antimicrobial Resistance. Antimicrob Agents Chemother 1995;Suppl:1-23.

2. Goldmann DA, Weinstein RA, Wenzel RP, et al. Strategies to prevent and control the emergence and spread of antimicrobial- resistant microorganisms in hospitals. A challenge to hospital leadership. JAMA 1996;275:234-40.

3. Swartz MN. Use of antimicrobial agents and drug resistance. N Engl J Med 1997;337:491-2.

4. Kunin CM. Perspective: resistance to antimicrobial drugs A worldwide calamity. Ann Intern Med 1993;118:557-61.

5. Addressing emerging infectious disease threats: a prevention strategy for the United States. Executive Summary. MMWR Morb Mortal Wkly Rep 1994;43(RR-5):1-18.

6. Conly J. Controlling antibiotic resistance by quelling the epidemic of overuse and misuse of antibiotics. Can Fam Physician 1998;44;1769-73.

7. Health Canada. Antibiotic Resistance. <http://www.hcsc.gc.ca/english/antires.htm > (Date of access August 2000).

8. World Health Organization. Overcoming Antimicrobial Resistance World Health Report on Infectious Diseases $2000<$ http://www.who.int/infectious-disease-report/2000/indexrpt2000_text.html > (Date of access August 2000).

9. Centers for Disease Control and Prevention. Draft Public Health Action Plan to Combat Antimicrobial Resistance $<$ http://www.cdc.gov/drugresistance/actionplan/index.htm > (Date of access August 2000).

10. Health Canada and the Canadian Infectious Disease Society. Controlling antimicrobial resistance an integrated action plan for Canadians. Can Commun Dis Rep 1997;23S7:1-32.

11. Canadian Committee on Antimicrobial Resistance. What's New? $<$ http://www.ccar-ccra.org> (Date of access August 2000).

12. Panlilio AL, Culver DG, Gaynes RP, et al. Methicillin-resistant Staphylococcus aureus in US hospitals 1975-1991. Infect Control Hosp Epidemiol 1992;13:582-6.

13. Vons A, Milatovic D, Wallrauch-Schwarz C, Rosdahl VT, Braveny I. Methicillin-resistant Staphylococcus aureus in Europe. Eur J Clin Microbiol Infect Dis 1994;13:50-5.

14. Low DE, Garcia M, Callery S, et al. Methicillin-resistant Staphylococcus aureus - Ontario. Can Dis Wkly Rep 1981;7:249-50.

15. Vortel JJ, Bell A, Farley JD, et al. Methicillin-resistant Staphylococcus aureus (MRSA) in a British Columbia hospital 1990. Can Dis Wkly Rep 1991;17:71-2.

16. Simor AE, Augustin A, Ng J, et al. Control of MRSA in a long-term care facility. Infect Control Hosp Epidemiol 1994;15:69-70.

17. The Canadian Nosocomial Infection Surveillance Program: Results of the first 18 months of surveillance for methicillinresistant Staphylococcus aureus in Canadian hospitals. Can Commun Dis Rep 1997;23:41-6.

18. Simor A, Ofner-Agostini M, Byrce E, et al. Methicillin-resistant Staphylococcus aureus (MRSA) in Canada: Five years of national surveillance. 40th Interscience Conference on Antimicrobial Agents and Chemotherapy, Toronto, September 17 to 20, 2000. (Abst 159)

19. Preston M, Borczyk A, Jamieson F. Epidemic methicillin-resistant Staphylococcus aureus strain - Ontario. Can Commun Dis Rep 1998;24:47-9.

20. Nosocomial enterococci resistant to vancomycin - United States 1989-93. MMWR Morb Mortal Wkly Rep 1993;42:597-9.

21. Martone WJ. Spread of vancomycin-resistant enterococci: why did it happen in the United States? Infect Control Hosp Epidemiol 1998;19:539-45.

22. Conly JM, Shafran S. Emerging epidemiology of vancomycinresistant enterococci in Canada. Can J Infect Dis 1997;8:182.

23. Lior L, Litt M, Hockin J, et al. Vancomycin-resistant enterococci on a renal ward in an Ontario hospital. Can Commun Dis Rep 1996;22:125-8

24. Ofner-Agostini ME, Conly J, Paton S, et al. Vancomycin-resistant enterococci (VRE) in Canada - Results of the Canadian Nosocomial Infection Surveillance Program 1996 VRE point prevalence surveillance project. Can J Infect Dis 1997;8:73-8.

25. Conly JM, Ofner ME, Paton S, et al. The emerging epidemiology of vancomycin-resistant enterococci in Canada 1993-1998: Results from the Canadian Nosocomial Infection Surveillance Program (CNISP) Passive Reporting Network. Can J Infect Dis 1999;10:38D. (Abst)

26. Johnston L, Conly J. The emerging epidemiology of vancomycinresistant enterococci in Canada revisited. Can J Infect Dis 2000;11:127-131. 
27. Simor AE, Louie M, Low DE. Canadian national survey of prevalence of antimicrobial resistance among clinical isolates of Streptococcus pneumoniae. Canadian Bacterial Surveillance Network. Antimicrob Agents Chemother 1996;40:2190-3.

28. Low D. Decreasing penicillin and macrolide resistance in Canada: who's driving whom? Canadian Bacterial Surveillance Network Newsletter December 1999:1-2.

29. Hoban DJ, Karlowsky JA, Nichol K, Palatnick LP Low De, Zhanel GG. Decreasing incidence of penicillin-resistant and multi-drug resistant Streptococus pneumoniae in Canada: Results of an ongoing natioal surveillance study 1997-2000. 40th Interscience Conference on Antimicrobial Agents and Chemotherapy. Toronto, September 17 to 20, 2000. (Abst 1808)

30. Baird RW. Antibiotic prescribing, controls, and antimicrobial resistance: an Australian experience. ALaaince for the Prudent Use Antibiotics Newslet 1997;15(4):1-6.

31. IMS HEALTH Canada <http://www.imshealthcanada.com> (Date of access August 2000).

32. Wang EE, Einarson TR, Kellner JD, Conly JM. Antibiotic prescribing for Canadian preschool children: evidence of overprescribing for viral respiratory infections. Clin Infect Dis 1999;29:155-60.
33. Levine MAH, Pradhan A. Can the health care system buy better antibiotic prescribing behaviour? CMAJ 1999;160:1023-24.

34. Conly J, Paton S, Forward K, et al. Reduction in oral antimicrobial cosumption on Canada. 40th Interscience Conference on Antimicrobial Agents and Chemotherapy. Toronto, September 17 to 20, 2000. (Abst 87)

35. Statistics Canada. Welcome to Statistics Canada. $<$ http://www.statcan.ca/english/Pgdb/People/popula.htm\#pop > (Date of access August 2000).

36. Hutchinson JM, Foley RN. Methods of physician remuneration and rates of antibiotic prescription. CMAJ 1999;160:1013-7.

37. Blondel-Hill EM, Fryters SR, Mitchell S, Carson MM, Tomney M. Do bugs need drugs? A community project for the wise use of antibiotics. 39th Interscience Conference on Antimicrobial Agents and Chemotherapy, San Francisco, September 26 to 29, 1999. (Abst 185)

38. Stewart J, Pilla J, Dunn L. Pilot study for appropriate anti-infective community therapy; effect of a guideline-based strategy to optimize use of antibiotics. Can Fam Physician 2000;46:851-9.

39. The bacteria won't die. Editorial. The Globe and Mail June 19, 2000:A12. 


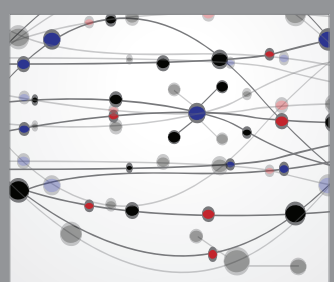

The Scientific World Journal
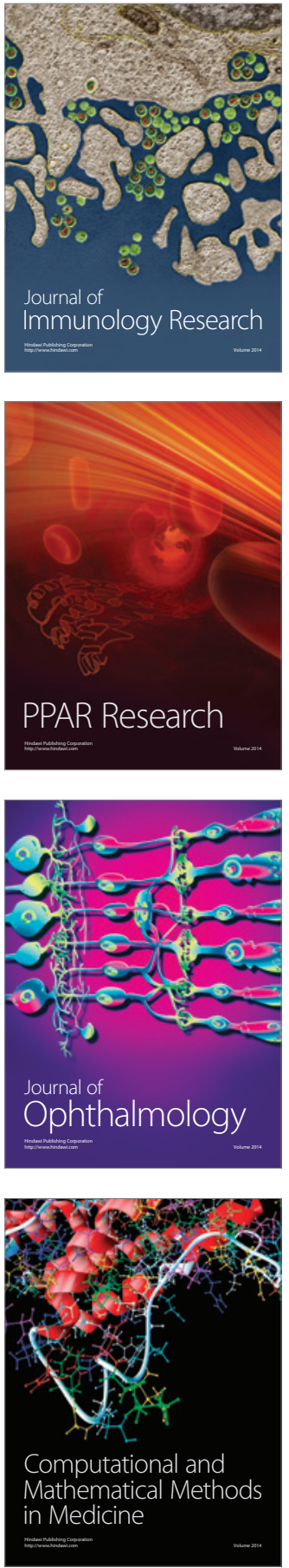

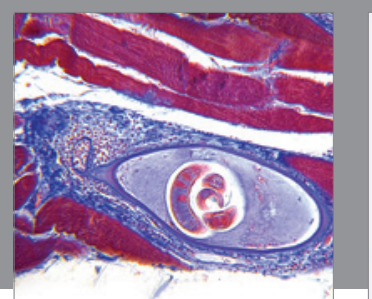

Gastroenterology Research and Practice

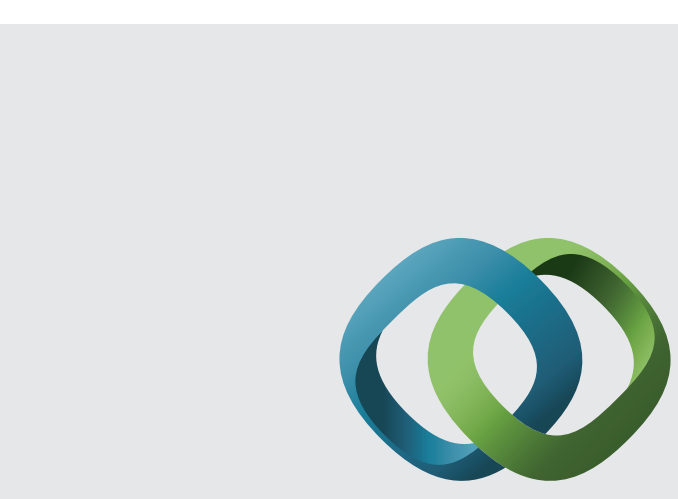

\section{Hindawi}

Submit your manuscripts at

http://www.hindawi.com
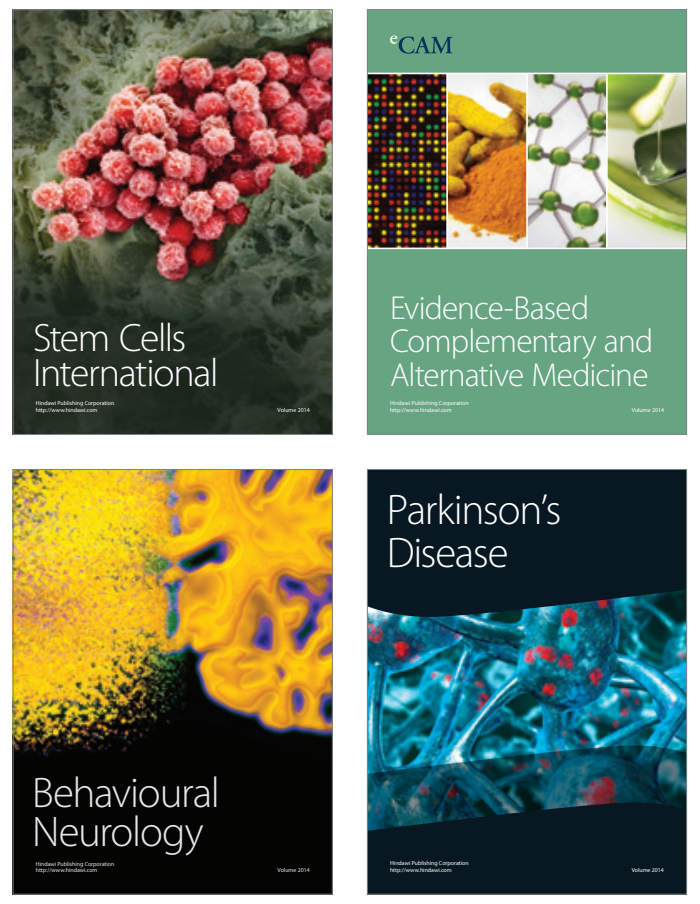
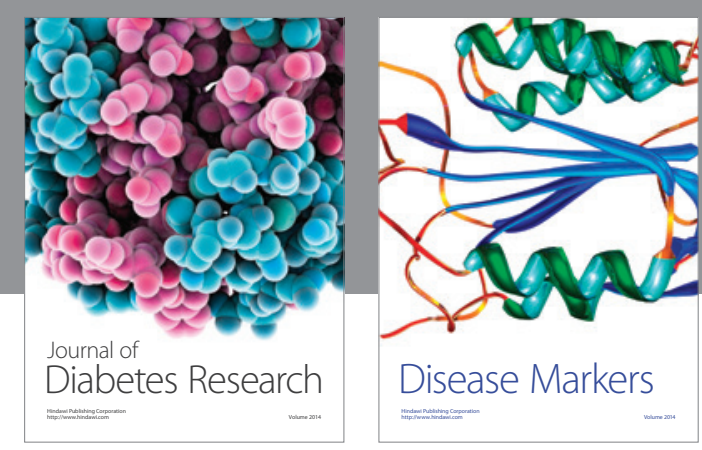

Disease Markers
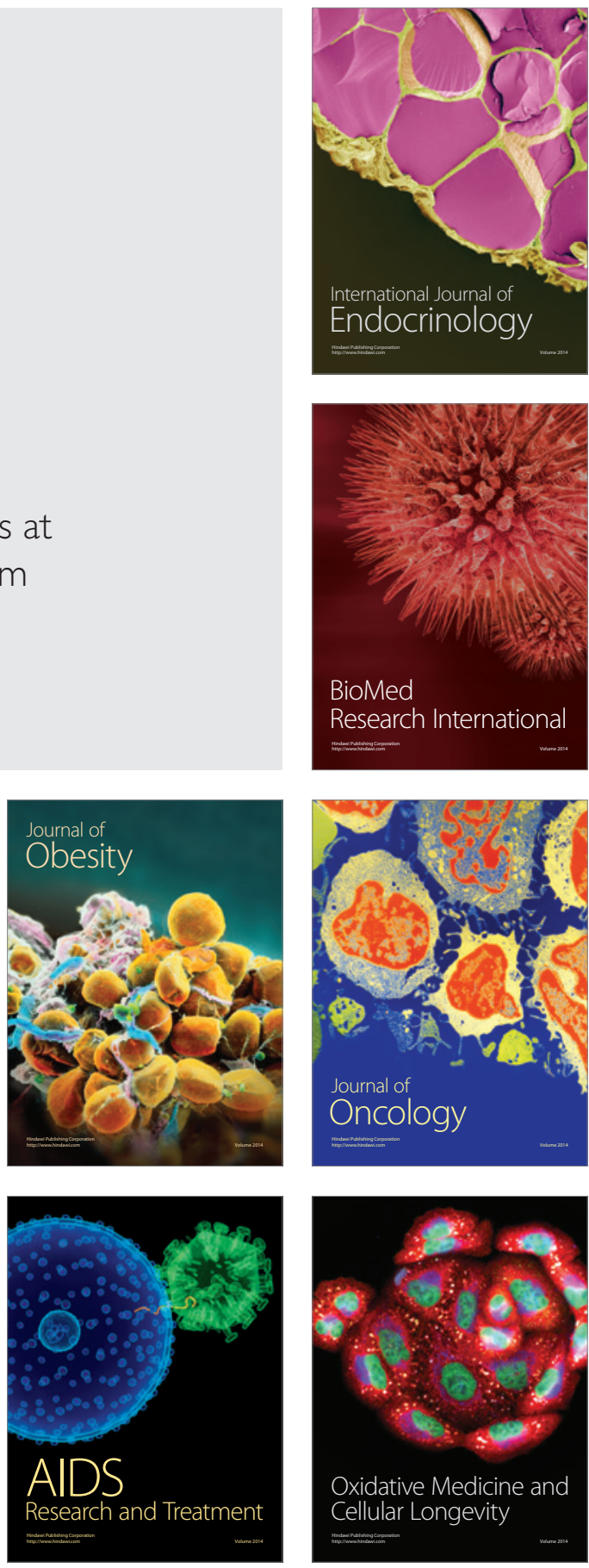